\title{
Growth performance, carcass characteristics and lipid profile of broiler chickens fed with graded levels of roselle calyx (Hibiscus sabdariffa L.)
}

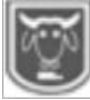

Awodola-Peters, O.O, and Yahaya, M.O

Federal College of Animal Health and Production Technology, Moor Plantation, Ibadan, Oyo State, Nigeria

Abstract ooawodolapeters@gmail.com; +234-8168168218

The study evaluated the effect of graded levels of roselle calyx (Hibiscus sabdariffa L.) on growth performance, carcass characteristics and lipid profile of broiler chickens. A total of 150 Arbor acre broiler birds were used for the six (6) weeks study and were randomly assigned to five treatments of thirty birds each, $\left(T_{1}, T_{2}, T_{3}, T_{4}\right.$ and $\left.T_{5}\right)$ which had broiler chicks fed with feed incorporated with roselle calyx as feed additive at $0 \%, 0.5 \%, 1 \%, 1.5 \%$, and $2 \%$ respectively. The birds were further randomly sub-divided into three replicates of ten birds each using a completely randomized design. Data were collected on feed intake, weight gain and feed conversion ratio was computed. At the end of the study, two birds were randomly selected from each replicate for the carcass characteristics and lipid profile evaluation. Data obtained were subjected to ANOVA and means were separated using the Duncan Multiple Range Test. The result obtained showed that the initial weight, average daily feed intake, total feed intake and carcass characteristics were not significantly different across the treatment means while the final weight, total weight gain and total feed intake value were significantly differed with the highest value of final weight at $T_{1}(1266.67 \mathrm{~g} / \mathrm{b})$ and lowest value at $T_{4}(1133.33 \mathrm{~g} / \mathrm{b})$. Also, result for lipid profile of the broiler chicken meat showed there was significant difference $(P<0.05)$ in the values obtained for low density lipoprotein, such that birds in control (that were not fed roselle calyx) had the highest value $(15.67 \mathrm{~g} / \mathrm{L})$ low density lipoprotein. It was therefore concluded that the inclusion level of roselle calyx up to $2 \%$ in broiler chicken diet improved carcass characteristics and lipid profile.

Keywords: Roselle calyx, growth performance, carcass characteristics, lipid profile, broiler chickens

\section{Introduction}

Poultry is used to describe any type of domesticated bird kept for meat and egg production such as domestic fowl and turkey (Akinsanmi, 1994). Broilers are good converters of feed, with average feed consumption of $5-6 \mathrm{~kg}$ in eight weeks in which $2 \mathrm{~kg}$ feed will produce $1 \mathrm{~kg}$ of body weight at ratio 2:1 (Babatunde and Fetuga, 1976). The production of high quality animal protein has been one of the major problem facing developing countries in which Nigeria is inclusive. This has led to serious malnutrition in people (Solanke,1989).

Roselle (Hibiscus sabdariffa L.) belongs to the family Malvaceae, it is an important annual crop grown successfully in tropical and sub-tropical climates (Copley, 2000).Roselle is a multi-purpose plant, whose outer leaves (calyx), also known as natal sorrel is frequently used in the production of jelly, jam, juice, wine, syrup, gelatin, pudding, cake, ice cream and flavoring. Its brilliant red color and unique flavor make it a valuable food product (Tsai and $\mathrm{Ou}, 1996)$. Roselle is an annual crop used in food, animal feed, nutraceuticals, cosmeceuticals and pharmaceuticals. The juice from the calyces is claimed to be a health-enhancing drink due to its high content of vitamin $\mathrm{C}$, anthocyanins and 


\section{Growth performance carcass characteristics and lipid profile of broiler chickens}

other antioxidants (Mohamad et al., 2002).Duke and Atchley (1984) reported that every $100 \mathrm{~g}$ of fresh calyx contains 2.85 $\mu \mathrm{g}$ vitamin $\mathrm{D}, 0.04 \mathrm{mg}$ vitamin $\mathrm{B} 1,0.06 \mathrm{mg}$ vitamin B2 and $0.5 \mathrm{mg}$ Vitamin B complex. More so, the calyx contains $84.5 \%$ water, $1.9 \%$ protein, $0.1 \%$ fat, $12.3 \%$ fibre, $0.12 \%$ ash in addition to high amounts of citric acid and anthocyanin. Numerous scientific studies have been done on the benefit of antioxidants in Hibiscus sabdariffa. The high level of anthocyanins and protocatechuic acid in Hibiscus sabdariffa were shown to have strong antioxidant effects (Lee et al., 2002; Blunden et al., 2005). Previous studies demonstrated an additional cardio protective effect of $H$. Sabdariffa via antioxidants mechanisms (Tangirala et al., 1995; Crawford et al., 1998; Rimm and Stamfer, 2000). Hibiscus sabdariffa extract also was reported to have inhibited Low-density lipoprotein (LDL) oxidation in vitro and decreased serum cholesterol levels in cholesterol-fed animals (Chen et al., 2003). Therefore, dietary roselle extract may reduce the incidence of atherosclerosis through their antioxidant activity (Lin et al., 2007). The plant is of increasing interest because of its application in health and medicine; therefore it is important to investigate the effect of roselle calyx on growth performance, carcass characteristics and lipid profile of broiler birds.

\section{Materials and methods Experimental site}

The experiment was conducted at Student Research Unit of Federal College of Animal Health and Production Technology Bora, Moor plantation, Ibadan.

Experimental birds and management

A total of 150,1-day old Arbor acre broiler birds were obtained from Federal College of Animal Health and Production
Technology Hatchery Moor plantation. The chicks were brooded for seven days on a deep litter system and were randomly assigned to five treatments (30 birds per treatment), three replicate of 10 birds each. Necessary vaccination programmes were carried out at appropriate times. Anti-stress was also administered to the birds on arrival and after each weighing.

\section{Experimental diet}

The birds were fed with commercial feed with roselle calyx included at graded levels. The birds were fed starter diet $(22.00 \%$ Crude protein, $2900 \mathrm{kcal} / \mathrm{kg}$ Metabolizable energy) from 1-21 days and finisher diet (18.00\% Crude protein and $2900 \mathrm{kcal} / \mathrm{kg}$ Metabolizable energy) from 22 to 42 days. Table 1 and 2 showsthe nutrient composition of the experimental diets (starter and finisher phase). Dried Roselle calyx was purchased at Bodija market also in Ibadan. The calyces were milled and stored in dried polythene bag until needed.

\section{Experimental treatment:}

Treatment 1: broiler chickens fed without inclusion of roselle calyx in their feed (control); Treatment 2: broiler chickens fed feed containing $0.5 \%$ inclusion of roselle calyx in their feed; Treatment 3: broiler chickens fed feed containing $1 \%$ inclusion of roselle calyx in their feed; Treatment 4: broiler chickens fed feed containing 1.5\% inclusion of roselle calyx in their feed and Treatment 5:broiler chickens fed feed containing $2 \%$ inclusion of roselle calyx in their feed

\section{Data collection}

Data was collected on feed intake, weight gain and feed conversion ratio for the performance characteristics.

\section{Carcass characteristics}

Six birds were randomly selected from each treatment, two birds per replicate for slaughter. The slaughtered birds were plucked and eviscerated manually.Dressed 


\section{Awodola-Peters and Yahaya}

carcass and internal organ such as thigh, drumstick, breast, heart, gizzard, liver and lungs weight were recorded as the percentage of the live weight.

\section{Lipid profile of meat}

$50 \mathrm{~g}$ of the breast meat from each replicate were taken to the laboratory for analysis of the lipid profile of the meat.

Lipid profile of blood serum

Two birds were selected at random from each replicate. The birds were bled using a sterilized disposable needle to aspirate $5 \mathrm{~mL}$ of blood sample from each bird for laboratory analysis of the lipid profile of the blood using the spectrophotometric method to examine the parameters which include: cholesterol, triglyceride, high density lipoprotein, low density lipoprotein Data collected were subjected to analysis of variance using SAS (2011) package and means were further separated using Duncan Multiple Range Test of the same software.

Table 1: Nutrient composition of experimental diet for starter broiler chicken

\begin{tabular}{lccccc}
\hline INGREDIENTS & $\mathbf{T}_{\mathbf{1}}(\mathbf{0 \%})$ & $\mathbf{T}_{\mathbf{2}}(\mathbf{0 . 5 \%}) \mathbf{R C}$ & $\mathbf{T}_{\mathbf{3}}(\mathbf{1 \%})$ & $\mathbf{T}_{\mathbf{4}}(\mathbf{1 . 5 \%}) \mathbf{R C}$ & $\mathbf{T}_{\mathbf{5}}(\mathbf{2 \%})$ \\
& $\mathbf{R C}$ & & $\mathbf{R C}$ & & $\mathbf{R C}$ \\
\hline Crude protein (\%) & 22.00 & 22.00 & 22.00 & 22.00 & 22.00 \\
Fats and oil (\%) & 6.00 & 6.00 & 6.00 & 6.00 & 6.00 \\
Crude fibre (\%) & 5.00 & 5.00 & 5.00 & 5.00 & 5.00 \\
Calcium (\%) & 1.00 & 1.00 & 1.00 & 1.00 & 1.00 \\
Phosphorus (\%) & 0.40 & 0.40 & 0.40 & 0.40 & 0.40 \\
Lysine (\%) & 1.20 & 1.20 & 1.20 & 1.20 & 1.20 \\
Methionine (\%) & 0.50 & 0.50 & 0.50 & 0.50 & 0.50 \\
Salt (\%) & 0.30 & 0.30 & 0.30 & 0.30 & 0.30 \\
Metabolizable & 2900 & 2900 & 2900 & 2900 & 2900 \\
Energy (Kcal/kg) & & & & & \\
\hline
\end{tabular}

RC: Roselle calyx, T: Treatment

Table 2: Nutrient composition of experimental diet for finisher broiler chicken

\begin{tabular}{lccccc}
\hline INGREDIENTS & $\mathbf{T}_{\mathbf{1}}(\mathbf{0 \%})$ & $\mathbf{T}_{\mathbf{2}}(\mathbf{0 . 5 \%})$ & $\mathbf{T}_{\mathbf{3}}(\mathbf{1 \%}) \mathbf{R C}$ & $\mathbf{T}_{\mathbf{4}}(\mathbf{1 . 5 \%}) \mathbf{R C}$ & $\mathbf{T}_{\mathbf{5}}(\mathbf{2 \%}) \mathbf{R C}$ \\
& $\mathbf{R C}$ & $\mathbf{R C}$ & & & \\
\hline Crude protein (\%) & 18.00 & 18.00 & 18.00 & 18.00 & 18.00 \\
Fats and oil (\%) & 6.00 & 6.00 & 6.00 & 6.00 & 6.00 \\
Crude fibre (\%) & 5.00 & 5.00 & 5.00 & 5.00 & 5.00 \\
Calcium (\%) & 1.00 & 1.00 & 1.00 & 1.00 & 1.00 \\
Phosphorus (\%) & 0.40 & 0.40 & 0.40 & 0.40 & 0.40 \\
Lysine (\%) & 0.85 & 0.85 & 0.85 & 0.85 & 0.85 \\
Methionine (\%) & 0.34 & 0.34 & 0.34 & 0.34 & 0.34 \\
Salt (\%) & 0.30 & 0.30 & 0.30 & 0.30 & 0.30 \\
Metabolizable & 2900 & 2900 & 2900 & 2900 & 2900 \\
Energy (Kcal/kg) & & & & & \\
\hline
\end{tabular}

RC: Roselle calyx, T: Treatment

\section{Results}

The effects of Roselle calyx on growth performance of broiler chickens is shown in Table 3,the parameters observed;initial weight, average daily feed intake and total feed intake were not significantly different across the treatments while the final weight, total weight gain and total feed intake value were significantly different. Total weight of birds in $\mathrm{T}_{1}$ was similar to those of birds in $\mathrm{T}_{2}$ and $\mathrm{T}_{3}$ but different from total weight of birds on $\mathrm{T}_{4}$ and $\mathrm{T}_{5}$, though $\mathrm{T}_{2}, \mathrm{~T}_{3}, \mathrm{~T}_{4}$ and $\mathrm{T}_{5}$ were not significantly different from each other. 
Growth performance carcass characteristics and lipid profile of broiler chickens

Table 3: Effect of roselle calyx on growth performance of broiler chickens

\begin{tabular}{lllllll}
\hline Parameters & $\mathbf{T}_{\mathbf{1}}$ & $\mathbf{T}_{\mathbf{2}}$ & $\mathbf{T}_{\mathbf{3}}$ & $\mathbf{T}_{\mathbf{4}}$ & $\mathbf{T}_{\mathbf{5}}$ & \\
& $\mathbf{( 0 \%} \mathbf{R c})$ & $\mathbf{( 0 . 5 \%} \mathbf{R c})$ & $\mathbf{( 1 \% R c )}$ & $\mathbf{( 1 . 5 \%} \mathbf{R c})$ & $(\mathbf{2 \%} \mathbf{R c})$ & $\mathbf{S E M}$ \\
\hline Initial weight(g/b) & 172.67 & 182.00 & 165.67 & 168.00 & 166.33 & 3.43 \\
Final weight gain (g/b) & 1266.67 & 1233.34 & 1200.00 & 1133.33 & 1200.00 & 20.63 \\
Total weight gain (g/b) & $1260.67^{\mathrm{a}}$ & $1151.33^{\mathrm{ab}}$ & $1201.0 \mathrm{a}^{\mathrm{ab}}$ & $1098.67^{\mathrm{b}}$ & $1133.67^{\mathrm{b}}$ & 20.70 \\
Average daily weight gain (g/b/d) & $29.91^{\mathrm{a}}$ & $25.32^{\mathrm{b}}$ & $28.26^{\mathrm{ab}}$ & $27.61^{\mathrm{ab}}$ & $27.42^{\mathrm{ab}}$ & 0.56 \\
Total feed intake (g/d) & 555.67 & 510.67 & 519.67 & 514.67 & 517.00 & 8.38 \\
Average daily feed intake (g/b/d) & 92.61 & 85.11 & 86.61 & 85.77 & 86.16 & 1.40 \\
Feed conversion ratio & $2.83^{\mathrm{b}}$ & $3.69^{\mathrm{a}}$ & $3.06^{\mathrm{ab}}$ & $3.12^{\mathrm{ab}}$ & $3.15^{\mathrm{ab}}$ & 0.11 \\
\hline
\end{tabular}

a,ab,b means of different superscripts along the same row are significantly different $(p<0.05)$

$\mathrm{Rc}=$ Roselle calyx $\quad \mathrm{g} / \mathrm{b}=$ gram per bird $\quad \mathrm{g} / \mathrm{b} / \mathrm{d}=$ gram per $\mathrm{bird}$ per $/$ day

Table 4: Effect of roselle calyx on the carcass characteristics and internal organs of broiler chickens

\begin{tabular}{lllllll}
\hline Parameters & $\mathbf{T}_{\mathbf{1}}(\mathbf{0} \% \mathbf{R c})$ & $\mathbf{T}_{\mathbf{2}}(\mathbf{0 . 5} \% \mathbf{R c})$ & $\mathbf{T}_{\mathbf{3}}(\mathbf{1 \%} \mathbf{R c})$ & $\mathbf{T}_{\mathbf{4}}(\mathbf{1 . 5 \%} \mathbf{R c})$ & $\mathbf{T}_{\mathbf{5}}(\mathbf{2 \%} \mathbf{R c})$ & $\mathbf{S E M}$ \\
\hline Live Weight (g) & 1365.67 & 1594.00 & 1297.33 & 1283.00 & 1210.67 & 50.46 \\
Bled Weight (g) & 97.70 & 98.27 & 97.80 & 97.98 & 97.99 & 0.13 \\
Plucked Weight (g) & 92.71 & 93.96 & 92.26 & 92.68 & 92.42 & 0.40 \\
Eviscerated Weight (g) & 84.38 & 77.71 & 77.73 & 78.46 & 77.26 & 1.00 \\
Dressed Weight (g) & 64.56 & 66.67 & 65.74 & 65.21 & 63.76 & 0.59 \\
Thigh (\%) & 10.78 & 11.64 & 10.67 & 10.98 & 10.75 & 0.20 \\
Drumstick (\%) & 11.37 & 11.09 & 11.57 & 11.42 & 11.06 & 0.14 \\
Breast (\%) & 20.79 & 21.70 & 21.18 & 21.79 & 20.94 & 0.39 \\
Heart (\%) & 0.54 & 0.53 & 0.49 & 0.47 & 0.44 & 0.03 \\
Gizzard (\%) & 3.34 & 3.52 & 3.80 & 3.75 & 3.76 & 0.13 \\
Empty gizzard (\%) & 2.39 & 2.52 & 2.63 & 2.61 & 2.59 & 0.07 \\
Liver (\%) & 2.21 & 2.14 & 1.98 & 2.10 & 2.04 & 0.07 \\
Lungs (\%) & 0.61 & 0.71 & 0.64 & 0.47 & 0.50 & 0.04 \\
\hline
\end{tabular}

SEM: Standard Error Mean $\quad$ T: Treatment Rc: Roselle calyx

Table 5 shows the effects of graded levels of rosellecalyxon the lipid profile of broiler chicken meat. The result showed that there was no significant effect of roselle calyx on the cholesterol, triglyceride and high

density lipoprotein of the broiler chicken. However there was significant effect of roselle calyx on low density lipoprotein, such that chicken that were not fed roselle calyx had the highest value for low density lipoprotein.

Table 5:Effect of graded levels of rosellecalyx on the lipid profile of broiler chicken meat

\begin{tabular}{|c|c|c|c|c|c|c|}
\hline Parameters & $\mathrm{T}_{1}(\mathbf{0 \%} \mathbf{R c})$ & $\mathbf{T}_{2}(0.5 \%$ Rc) & $\mathrm{T}_{3}(\mathbf{1} \% \mathrm{Rc})$ & $\mathrm{T}_{4}(1.5 \% \mathrm{Rc})$ & $\mathrm{T}_{5}(\mathbf{2 \%} \mathrm{Rc})$ & SEM \\
\hline Cholesterol (g/L) & 76.87 & 77.63 & 84.37 & 87.77 & 80.00 & 3.11 \\
\hline Triglyceride (g/L) & 244.70 & 218.63 & 239.70 & 156.35 & 233.53 & 12.01 \\
\hline High Density Lipoprotein (g/L) & 22.23 & 23.40 & 26.17 & 25.97 & 26.77 & 2.41 \\
\hline Low Density Lipoprotein (g/L) & $15.67^{\mathrm{a}}$ & $13.27^{\mathrm{ab}}$ & $15.50^{\mathrm{ab}}$ & $6.70^{b}$ & $10.24^{\mathrm{ab}}$ & 3.08 \\
\hline
\end{tabular}

a,b,c: Means with different superscript along the same row are significantly different $(\mathrm{p}<0.05)$.

SEM: Standard Error Mean T: Treatment $\quad(\mathrm{g} / \mathrm{L})$ : Gram per Litre Rc: roselle calyx 


\section{Awodola-Peters and Yahaya}

Table 6 shows the lipid profile of blood serum from birds fed graded levels of the Roselle calyx. The results indicated that there were no significant difference $(\mathrm{P}>0.05)$ in the values across the treatment means.

Table 6: Effect of graded levels of rosellecalyx on the lipid profile of blood serum from broiler chickens

\begin{tabular}{lcccccc}
\hline Parameters & $\mathbf{T}_{\mathbf{1}}(\mathbf{0 \%} \mathbf{R c})$ & $\mathbf{T}_{\mathbf{2}}(\mathbf{0 . 5 \%} \mathbf{R c})$ & $\mathbf{T}_{\mathbf{3}}(\mathbf{1 \%} \mathbf{R c})$ & $\left.\mathbf{T}_{\mathbf{4}} \mathbf{( 1 . 5 \%} \mathbf{R c}\right)$ & $\mathbf{T}_{\mathbf{5}}(\mathbf{2 \%} \mathbf{R c})$ & $\mathbf{S E M}$ \\
\hline Cholesterol(g/L) & 148.43 & 141.57 & 108.76 & 115.66 & 134.63 & 9.20 \\
Triglyceride(g/L) & 302.33 & 299.21 & 339.52 & 246.50 & 334.87 & 16.21 \\
High Density Lipoprotein (g/L) & 70.44 & 71.07 & 71.07 & 62.63 & 67.18 & 1.58 \\
Low Density Lipoprotein(g/L) & 26.12 & 27.07 & 24.80 & 24.37 & 22.58 & 1.33 \\
\hline
\end{tabular}

SEM: Standard Error Mean $\quad$ T: Treatment $\quad(\mathrm{g} / \mathrm{L})$ : Gram per Litre $\quad$ Rc: roselle calyx

\section{Discussion}

The growth performance as shown in Table 4 revealed significant $(\mathrm{P}>0.05)$ difference on average daily weight gain of the chickens. Chickens that were not fed Roselle calyx $\mathrm{T}_{1}$ (Control) had the highest daily weight gain and average daily weight gain. However, there was no significant effect of Roselle calyx on initial weight, final weight gain, total daily feed intake and average daily feed intake of the chicken. This observation was similar to the report of Unigwe (2011) who reported highest average daily weight gain of chicken when graded level of Hibiscussabdariffa $L$. extract were administered to broiler chicken.

Feed conversion ratio is a measure of feed utilization or the efficiency of converting unit feed into unit gain. Feed conversion ratio showed that $T_{1}$ has the least value than any other treatment. Table 5 indicated that therewas no significant $(\mathrm{P}>0.05)$ difference in the valuesobtained for all the carcass characteristics parameters examined across the treatments. The observed similarities in carcass characteristics were as a result of nutrient balance in the experimental feeds which were within recommended range for broilers NRC (1994) and the nutrient constituents (Shaheenet al., 2012). Organ weights in the different dietary treatment group were similar to those earlier reported by Zhou et al. (2009). Though the results indicated that therewas no significant difference in the valuesobtained for all the lipid profile of blood serum examined across the treatments, there were numerical differences in the values such that the treatments fed with graded level of Roselle had low cholesterol value when compared to the control $\left(\mathrm{T}_{1}\right)$. The blood serum values for all the dietary treatment groups confirm the nutritional adequacy of the experimental diets.

Though, there was no significant difference in the lipid profile parameters of the meatmeasured (cholesterol, triglyceride and high density lipoprotein) except for low density protein (LDL).There were significant differences in the values of low density lipoprotein such that control $\left(\mathrm{T}_{1}\right)$ had a higher significant value $(15.67 \mathrm{~g} / \mathrm{L})$ of low density lipoprotein than the other treatments $\left(\mathrm{T}_{2} ; 13.27 \mathrm{~g} / \mathrm{L}, \mathrm{T}_{3} ; 15.50 \mathrm{~g} / \mathrm{L}, \mathrm{T}_{4}\right.$; $\left.6.70 \mathrm{~g} / \mathrm{L}, \mathrm{T}_{5} ; 10.24 \mathrm{~g} / \mathrm{L}\right)$ fed with inclusion of roselle calyx. The values obtained were comparable to those reported byKwariet al. (2011) who fed fermented roselle to broiler chickens.

\section{Conclusion}

It was concluded from this study that inclusion level of Roselle calyx up to $2 \%$ compared favorably than the control.Based on the result obtained for the lipid profile of the meat, it was observed that the inclusion of roselle calyx at the graded levels 


\section{Growth performance carcass characteristics and lipid profile of broiler chickens}

increased the High Density Lipoprotein (HDL) and reduced the Low Density Lipoprotein (LDL) except for the control. This showed that the inclusion of roselle calyx in the diet has the potential to reduce the risk of hyperlipidemia and its associated diseases

\section{References}

Akinsanmi, A. O. 1994.Senior Secondary Agricultural Science 5th Edition Longman Publisher. pp. 110

Babatunde, G. M. and Fetuga, B.L. 1976. Methionine supplementation of low protein diets for broiler chickens in the tropics. Pp. 463-469

Blunden,G., Badreldin, H. A. and Naser A. 2005. Phytochemical, $\mathrm{Pharmacological}$ and Toxicological Aspects of Hibiscus sabdariffa L.: A Review. Phytotherapy Research, 19, 369375.

Copley, L.S. 2000.An introduction to the botany of tropical crops. Longman Group, U.K.

Chen, C.C, Hsu, J.D, Wang, S.F., Chiang, H.C., Yang, M.Y., Kao, E.S., Ho, Y.C. and Wang, C.J.2003. Hibiscus sabdariffa extract inhibits the development of atherosclerosis in cholesterol-fed rabbits. Journal of Agriculture Food; 51: 5472-5477.

Crawford, R.S., Kirk, E.A., Rosenfeld, M.E., LeBoeuf, R.C. and Chait, A. 1998. Dietary antioxidants inhibit development of fatty streak lesions in the LDL receptordeficient mouse. Arteriosclerosis, Thrombosis, and Vascular Biology, 18, 1506-1513.

Duke, J . A . and A t c h le y, A.A.1984.Proximate Analysis. In: Christie BR (Ed). The Handbook of
Plant Science in Agriculture, CRC press Inc., Boca Raton, FL., Page: 427-434.

Kwari, I.D., Igwebuike, J.U., Mohammed, I.D and Diarra, S.S. 2011. Growth, haematology and serum chemistry of broiler chickens fed raw or differently processed Roselle calyx (Hibiscussabdariffa) seed meal in a semi-arid environment. I.J.S.N;2(1):22-27.

Lee, M.J., Chou, F.P., Tseng, T.H., Hsieh, M.H., Lin, M.C. and Wang, C.J. 2002. Hibiscus protocatechuic acid or esculetin can inhibit oxidative LDL induced by either copper ion or nitric oxide donor. Journal Agriculture and Food Chemistry, 50, 2130- 2136.

Lin, H.H., Chen, C.C., Lin, M.C., Chou, M.C. and Wang, C.J. 2007. Hibiscus sabdariffa extract reduces serum cholesterol in men and women. Nutrition Research, 27, 140-145.

Mohamad, O., Mohd. Nazir, B., Abdul Rahman, M. and Herman, S. 2002. Roselle: A new crop in Malaysia. Bio Malaysia: A grand International Biotechnology Event. Bulletin.Kuala Lumpur

NRC (National Research Council) 1994. Nutrient requirements of p o u ltry.9th Re vised edition.National Academy of science, Washington, D. C.

Rimm, E.B., and Stamfer, M.J. 2000. Antioxidants for vascular disease.Medical Clinics of North America, 84, 239-249.

SAS. 2011. Statistical Analysis System Institute User's Guide. 9th Edition, North Carolina, USA

Shaheen, M.A., El Nakhlawy F.S. and Al- 
Shareef A.R. 2012. Roselle (Hibiscus sabdariffa L.) seeds as unconventional nutritional source. African Journal of Biotechnology.1(41).9821-9824.

Solanke, J. 1989. Nutritional evaluation and elimination of toxic principles in wild yam (Dioscorea spp.).Tropical and Subtropical Agro-ecosystems, (8), 319- 225.

Tangirala, R.K., Casanada, F., Miller, E., Witztum, J.L., Steinberg, D. and Palinski, W. 1995.Effect of the antioxidant N, NV-diphenyl 1, 4phenylenedi-amine (DPPD) on atherosclerosis in apoE-deficient mice.Arteriosclerosis Thrombosis and Vascular Biology, 15, 16251630.

Tsai, J. and Ou, M. 1996.Colour degradation of dried roselle during storage. Food Science; 23: 629-640.
Unigwe, C. R. 2011.Effect of graded levels of Hisbiscus sabdariffa Linn (Roselle) calyx extract on growth performance and haematology of broiler chicken.Global Research Journal of Science 1:78-81

Zhou, T. X., Chen, Y. J., Yoo, J. S., Huang, Y., Lee, J. H., Jang, H. D., Shin, S.O., Kim, H. J., Cho, J. H. and Kim I. H.2009. Effects of c h i t o oli gos a c charide supplementation on performance, blood characteristics, relative organ weight, and meat quality in broiler chickens.Poultry Science; 88(3):593-600.

Received: 8th September, 2017 Accepted: 30th November, 2017 